\title{
Augmentation-Mastopexy after Massive Weight Loss
}

\author{
ILya V. Sergeev, $\mathrm{PhD}^{1}$; Edward V. Shihirman, $\mathrm{PhD}^{1}$; Tagir R. Fayzullin, $\mathrm{PhD}^{1,2 *}$ \\ 'The clinic of plastic surgery "Dr.Plastic" \\ ${ }^{2}$ The M. Vladimirsky Moscow Regional Research Clinical Institute (MONIKI) \\ Moscow, Russia
}

\begin{abstract}
This paper presents an assessment of the results of mastopexy surgery carried out by using the technique of autologous breast enlargement axillary lateral flap, which the authors developed for patients who have suffered a decline in breast volume, as a result of massive weight loss after bariatric surgery. The mastopexy was carried out by the improved method with preliminary Doppler ultrasound of the perforating branches of intercostal arteries in women after a significant reduction in body weight. This method provides a good aesthetic result with the correct position of the nipple and a satisfactory volume of the breast and with a simultaneous removal of excessive skin flaps and excess fat in the anterolateral area of the chest. (Int J Biomed. 2016; 6(1):4647.).
\end{abstract}

Keywords: mammary glands; augmentation-mastopexy; weight loss; bariatric surgery.

\section{Introduction}

A significant reduction in weight of overweight women leads to the appearance of areas with a large excess of skin and subcutaneous tissues. These involutional changes of the breast can be a source of aesthetic dissatisfaction in the patient $[1,2]$. Loss of breast volume with a significant reduction in body weight encourages ptosis and non-aesthetic changes in configuration of the entire surface of the upper half of the body [3]. Reducing the volume of the breast, performing only standard mastopexy, is generally insufficient to restore the breast to an aesthetically acceptable form, since such restoration requires a significant increase in the volume of the breast [4]. The results of mastopexy and reduction mammoplasty are largely determined by the presence or absence of breast asymmetry in the outcome [5]. In addition, patients are often worried about the decrease in volume of the tissues surrounding the implant, which leads to unfavorable relief of their contours [2,6,7].

The aim of this study was to evaluate the results of mastopexy carried out by an improved method using preliminary Doppler ultrasound of perforating branches of intercostal arteries in women after a significant reduction in body weight.

*Corresponding author: Tagir R. Fayzullin, PhD, Associate Professor of the Oncology and Thoracic Surgery Department of the MONIKI; Moscow, Russia.E-mail: Tagir.Fayzullin@,rambler.ru

\section{Materials and Methods}

The study included 30 patients who underwent bariatric surgery to reduce body weight and applied for correction of the mammary glands. The mean age of women was 45.8 years. The average period after bariatric surgery was 2.4 years, average weight loss $-71 \mathrm{~kg}$, mean BMI during the inspection $-30.6 \mathrm{~kg} / \mathrm{m}^{2}$.

Inclusion criteria were that patients had to meet the following criteria:

-Underwent bariatric surgery for weight loss;

- The preservation of sustainable weight control over the past 6 months;

-Indications for mastopexy surgery;

-The informed approval of patients for mastopexy surgery.

All patients underwent a vertical mastopexy with shearing and displacement of the additional lateral flap of the breast. The surgical field markup in a standard posture was performed before surgery in all cases. After the standard vertical mastopexy, the intervention was supplemented by shearing and sewing the lateral axillary flap. The base of the free flap was determined along the anterior axillary line, with a width of 6 to $8 \mathrm{~cm}$.

Cutaneous perforating arteries were identified by using Doppler ultrasound of an anterior axillary area, in the preoperative period, with the location of blood vessels marked 
on the skin. The length of the flap was generally from 15 to 20 $\mathrm{cm}$, depending on the amount of excess skin and fatty tissue. The longitudinal axis of the flap was parallel to the upper edges of the slightly oblique deviation in the distal end.

The antibiotic prophylaxis was conducted in the preoperative period in all cases. The position of the patient was changed slightly after the anesthesia induction for better access to the lateral and posterolateral surface of the chest.

The musculocutaneous flap was isolated from its posterior edge toward the anterior edge. The perforating branches of intercostal arteries were carefully identified and preserved along the lateral chest wall. Primary closure of the lodge flap was performed with the use of the vicryl filaments 2-0 for deep layers and a monoacryla suture 3-0 for subcutaneous tissues and skin.

The subcutaneous pocket for the flap was formed above the fascia of the pectoral muscle in the direction of the clavicle. All perforating arteries supplying the flap were carefully preserved. After sufficient mobilization, the flap was rotated up to $90^{\circ}$ around the lower leg, which was previously created, a desired image was set and then fixed to the chest.

During the postoperative period, patients were invited for inspection after approximately one week, one month, three months, six months, and a year. The result of the operation was estimated based on the results of the flap engraftment, aesthetic results of operations, the number of re-operations and patients' subjective judgment of the operation results.

\section{Results and Discussion}

After the first week, in all cases, in the operated area the soft tissue swelling interstitial hematomas of various prevalence appeared, which were resolved usually by themselves after 1-2 months. Interstitial seromas with a volume of $100 \mathrm{ml}$ were found in two patients. None of the cases showed signs of necrotic changes in adipose tissue or tissue flap, wound healing complications or skin necrosis. Complications from the donor area were not identified.

After one month and six months after surgery, we diagnosed a good position of the nipple and a satisfactory volume of the breast; thus the excessive amounts of "free" skin and subcutaneous fat in the anterolateral area of the chest were eliminated (Photo 1).

Patients were satisfied with the improvement of the forms and the increasing size of the breast, while reducing the skin excess and fatty tissue in $100 \%$ of cases. A vertical scar was cosmetically acceptable to all patients. During the first year after the surgery, we did not identify any complications of augmentation-mastopexy. In all cases, the displaced tissue flap remained unstrained and homogeneous in comparison with the surrounding breast tissue, and the border between them was practically not determined during the palpation.

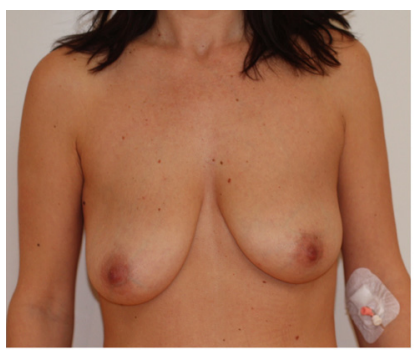

A. Before surgery

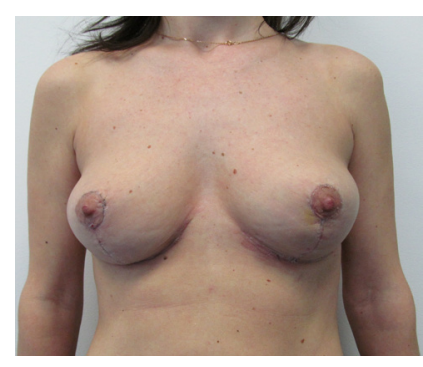

B. After surgery (3rd week)
Photo 1.

(A) Before and (B) after a vertical mastopexy with shearing and displacement of the additional lateral flap of the breast

\section{Conclusion}

Thus, preoperative identification of perforating vessels of the intercostal arteries provides a $100 \%$ engraftment of the lateral axillary flap at augmentation-mastopexy. This technique of augmentation-mammoplasty in conjunction with standard mastopexy makes it possible to achieve the satisfactory breast volume and the improved upper body contour after massive reduction in body weight.

\section{Competing interests}

The authors declare that they have no competing interests.

\section{References}

1. Adams WP Jr. The process of breast augmentation: four sequential steps for optimizing outcomes for patients. Plast Reconstr Surg. 2008; 122(6):1892-900.

2. Glicenstein J. [History of augmentation mammaplasty]. Ann Chir Plast Esthet. 2005; 50(5):337-49. [Article in French]. 3. Schoeller T, Meier R, Otto-Schoeller A, Wechselberger G, Piza-Katzer H. Medial thigh lift free flap for autologous breast augmentation after bariatric surgery. Obes Surg. 2002;12(6):831-4.

4. Araco A, Gravante G, Araco F, Delogu D, Cervelli V, Walgenbach K. A retrospective analysis of 3,000 primary aesthetic breast augmentations: postoperative complications and associated factors. Aesthetic Plast Surg. 2007; 31(5):532-9. 5. Saratovtseva GY Secondary breast asymmetry after a mastopexy and reduction mammoplasty. Abstract of $\mathrm{PhD}$ Thesis. Moscow; 2011. [ Abstract in Russian].

6. Milanov NO, Chausheva SI, Alyautdin SR, Kraskovsky FYa. Poland's syndrome: the choice of the surgical strategy Annals of Plastic, Reconstructive and Aesthetic Surgery. 2014; 2:35-41. [Article in Russian].

7. Lai YL, Yu YL, Centeno RF, Weng CJ. Breast augmentation with bilateral deepithelialized TRAM flaps: an alternative approach to breast augmentation with autologous tissue. Plast Reconstr Surg. 2003; 112(1):302-8. 